\title{
SÍNDROME DE BURNOUT RELACIONADA AO IMPACTO DO ESTRESSE NA VIDA DO POLICIAL MILITAR
}

\author{
Thais Felipe de Sousa ${ }^{1}$ \\ Willer Werneck Xavier Barroso ${ }^{2}$
}

RESUMO: O impacto que o estresse continuado, no ambiente de trabalho, traz para os profissionais consequências negativas para sua vida laboral e pessoal. O policial militar faz parte de um grupo de profissionais que se encontram cotidianamente sob o efeito de elementos estressores. O objetivo é analisar as principais causas e consequências do desses elementos em policiais militares, identificando o que as instituições apresentam como prevenções primárias e secundárias, por meio de resultados de pesquisas publicadas na última década. O método utilizado foi da revisão bibliográfica, a partir da análise dos resultados de 17 estudos publicados, sendo 14 (trasnversais) 03 (revisão da literatura) o que possibilitou uma visão mais abrangente do tema. A contribuição para compreensão de que a luta constante do profissional para lidar com a influência devastadora que o estresse continuado, presente no ambiente de trabalho ou das relações nele estabelecidas, é o que leva ao estabelecimento da Síndrome de Burnout. As consequências normalmente são agravadas, porque na falta da atenção primária quando aparecem os primeiros sinais e sintomas, não são apresentadas propostas de intervenção necessárias, sendo percebida pelas instituições somente no agravamento dos casos. Essa problemática comprova a importânica do desenvolvimento de mais estudos na área, pela validação na análise dos resultados, que esse agravamento $e$ responsabilização desses indíduos trazem repercussão na vida profissional e familiar. Considera-se que os objetivos foram alcançados, pela contibuição de trazer para discussão alguns agravantes identificados na análise dos resultados: convivência cotidiana com a violência e morte, exaustiva rotina de trabalho, desigualdade na questão de gênero (feminino), desvalorização social e profissional, falta de espaço colaborativo, instrumentos de trabalhos que deixam a desejar em qualidade e quantidade, entre outros. A psicologia como ciência tem como foco de estudo o comportamento humano e suas interações, portanto incentiva a ampliação dos estudos e a reflexão sobre a garantia da saúde física e mental dos profissionais que cuidam da segurança da população.

Palavras-chave: Estresse. Ambiente de trabalho. Burnout. Polícia Militar.

\footnotetext{
I Graduada em Psicologia pela Universidade Paulista Brasília (2020); Psicóloga inscrita no CRP/or sob o no ol/23796; Formação em Sexologia Forense pela Pontifícia Universidade Católica do Goiás (2020). Email: admsousa97@gmail.com.

${ }^{2}$ Psicólogo especialista em Terapia Cognitiva Comportamental, pós-graduando em Neuropsicologia pelo Instituto Brasiliense de Análise do Comportamento (IBAC) e mestrando em psicologia Clínica e da Saúde pela Universidad Europea del Atlántico (UNEATLANTICO)/Fundação universitária Iberoamericana (FUNIBER)
} 
ABSTRACT: The impact that continued stress on the work environment has for the professionals negative consequences for their work and personal life. The military police is a group of professionals who meet daily under the effect of stressors. The objective is to analyze the main causes and consequences of these stressor elements in military police, identifying what the institutions present as primary and secondary preventions, pointed out in the results of research published in the last decade. The method used was the bibliographic review, based on the analysis of the results of 17 published studies, 14 (cross-sectional) 03 (literature review), which enabled a more comprehensive view of the theme. The contribution to understanding that the constant struggle of the professional to deal with the devastating influence that the continued stress, present in the work environment or in the relationships established in it, leads to the establishment of the Burnout Syndrome. The consequences are usually aggravated, because in the absence of primary care - when the first signs and symptoms appear, necessary intervention proposals are not presented, being perceived by the institutions only in the aggravation of cases. This problem confirms the importance of developing more studies in the area, as evidenced in the analysis of the results, that this aggravation and commitment of these individuals has repercussions on professional and family life. It is considered that the objectives were achieved, due to the contribution of bringing to discussion some aggravating-stressors identified in the analysis of the results: daily living with violence and death, exhaustive work routine, inequality in the issue of gender (female), social devaluation and professional, lack of collaborative space, work tools that leave something to be desired in quality and quantity, and others. Psychology as a science that focuses on human behavior and its interactions. And, encourages broadening of studies and reflection on ensuring the physical and mental health of professionals who take care of citizen security.

Keywords: Stress. Workplace. Burnout. Military Police.

\section{INTRODUÇÃO}

\section{I.I. Apresentação}

No Brasil, a segurança é um aspecto fundamental para a organização e desenvolvimento do país, e em grande parte essa segurança é feita por policiais civis e militares que estão sempre de prontidão, correndo riscos para sua vida e de seus familiares, já que em seu cotidiano, eles lidam com muita violência, opressão, diversos fatores que causam estresse e também medo da morte. Cenário e situação, que de acordo com a literatura, em longo prazo se tornam extremamente prejudiciais, podendo desencadear a Síndrome de Burnout (SB), que se caracteriza por um distúrbio psíquico em que há grande tensão emocional e estresse causados por fatores geradores de tensão/apreensão e desgastantes nas condições de trabalho (SARTORI; CASSANDRE; VERCESI, 2008). 
O reconhecimento de que a vida laboral do policial é deveras estressante e, a rotina nesse cenário de trabalho pode ser um indicativo para o desenvolvimento da $\mathrm{SB}$ entre esses profissionais. Cabem destacar como exemplo, pesquisas realizadas apontando os seguintes resultados, que apresentam como índices: 91,7\%, sempre ou às vezes percebiam-se estressados; $88,3 \%$ ao fim do dia sentiam-se emocionalmente cansados; 62,5\% percebiam-se agressivos no trabalho; 20,8\% pensavam em suícidios (OLIVEIRA; SANTOS, 20I0).

O profissional da polícia que desenvolve a SB apresenta algumas alterações de comportamento, podendo vir a ocorrer, como por exemplo, aumento da probabilidade de abordagens mais brutas, abuso de poder e até mesmo consequências mais severas, como agressões ou até mesmo suicídio (SARTORI; CASSANDRE; VERCESI. 2008).

Segundo o Ministério da Sáude (BRASIL, 2018), os agentes estressores no ambiente de trabalho pode desencadear o aparecimento de doenças psicossomáticas, assim como outros sintomas e sinais de desequilibrios de comportamento.

Partindo do principio defendido por Couto e Gomes (2012), "o campo de saúde do trabalhador tem potencial efetivo sobre as políticas e ações de saúde, mobilizando transformação das relações saúde-ambiente-trabalho" (p.192). No sentido de harmonizar a saúde física e mental do trabalhador, estudos na área de psicologia contribuem na busca de mediação nas interações entre os sujeitos e os cenários de convívio minimizando as situações de adoecimento (COUTO; GOMES, 2012).

$\mathrm{A} S B$ é adquirida por meio de fatores estressantes que desgastam e afetam a condição física e psicológica dos indivíduos em situações diretamente relacionadas ao ambiente de trabalho. Para Oliveira e Santos (2010), os sintomas que geralmente aparecem e podem ser percebidos são: "taquicardias, tensão muscular, mãos frias e suadas, sensação de nó e dor no estômago, ombros ligeiramente levantado, e estado de alerta permanente" (p. 229).

Desta maneira, um agente policial pode se encontrar em uma rotina de trabalho e vida pessoal em que o estresse é estimulado periodicamente, pois no dia-adia a pessoa que trabalha na área da segurança pública, mesmo quando está em horário de folga, sem farda e longe de seu local de trabalho, continua sendo reconhecido como 
um policial, o que o leva a estar a todo o momento com uma postura de defesa, em que uma excessiva exposição a fatores estressantes leva os agentes policiais a terem destaque entre os servidores que mais sofrem estresse (SARTORI, CASSANDRE, VERCESI, 2008).

Dessa forma, deve-se atentar para o fato de que as pessoas que cuidam da segurança dos cidadãos, o que constitui a relevância desse estudo, também possuem a necessidade de ter cuidados e avaliações de como estão as suas condições de saúde, pois além de sua saúde ser importante como individuo, ela reflete diretamente não somente no cotidiano do policial, mas na sociedade como um todo.

\subsection{Tema/ Levantamento bibliográfico}

As relações entre os profissionais e o ambiente de trabalho, quando recebem fortes influências de elementos estressores podem causar o adoecimento daqueles. A psicologia e o seu interesse na harmonização entre sujeitos e o meio, preocupa-se com o avanço nos casos de Síndrome de Burnout (SB) entre policiais militares, delimitando nos fatores de risco e prevenção primária e secundária.

O Policial Militar, indispensável no combate à criminalidade, nos vários cenários do cotidiano do Brasileiro, é uma figura essencial no sistema de segurança pública. O trabalho desempenhado por esses profissionais acontece em meio à violência, passando por riscos e situações estressantes, podendo desencadear alterações psicossomáticas no indivíduo e afetar sua saúde, carreira profissional e vida pessoal e social (FARIA, 2000).

O êxito de atividades depende do ambiente e da motivação para o profissional desenvolver um bom trabalho, ser produtivo e alcançar os resultados esperados. Um dos pontos negativos que interferem no clima de qualquer organização são os elementos estressores, que cooperam para que o profissional se sinta desmotivado para desenvolver suas atividades e ser produtivo. É imprescindivel saber o conceito de estresse, os fatores estressantes e como pode afetar o organismo dos agentes policiais que lidam constantemente com situações ameaçadoras e de perigos (BRASIL, 2015). 


\section{Tipos e influências do estresse em profissionais}

O conceito de estresse evoluiu ao longo dos anos. O termo "estresse" foi introduzido no campo da saúde entre os anos 1920 e 1930 , pelo médico e fisiologista Walter Cannon, porém foi o pesquisador e médico austro-húngaro naturalizado canadense Hans Selye que sistematizou e popularizou seu uso a partir dos anos 1950. Para Castro (2018) o termo foi escolhido para referir-se "às mudanças psicofisiológicas que se produzem no organismo em resposta a uma situação desagradável ou adversa" (p. 243).

O estresse de fato é considerado uma doença que afeta muitas pessoas. Os fatores estressantes estão presentes em todas as situações cotidianas, que são consideradas desafiantes, exigindo assim que o nosso organismo dê uma resposta a essa situação. Cabe ainda destacar achados em seus estudos que indicam que são vários fatores estressores, e o que afeta uma pessoa pode não estressar outra (LIPP, 200I).

Apesar de ser uma atitude biológica necessária ao indivíduo, o estresse descontrolado impacta negativamente, pois em excesso pode causar diferentes reações físicas e emocionais, prejudicando o funcionamento fisiológico do indivíduo e trazendo implicações para a saúde. Formigamento nas extremidades do corpo, úlcera, batimentos cardíacos acelerados, hipertensão arterial e gastrite, são alguns exemplos de sintomas físicos na pessoa que está com estresse excessivo. Angústia, hipersensibilidade emotiva, tiques nervosos, perda do senso de humor, são sintomas emocionais decorrentes do estresse (BRASIL, 2015).

O estresse é considerado uma reação do corpo que interfere física e mentalmente provando desconfortos e agravos dependendo da situação de uma adaptação grande a um evento ou situação de importância (SILVA, SALLES, 20I6, p. 247).

Assim, dependendo do grau dessa reação há interferência negativa diretamente no ambiente de trabalho. O ambiente de trabalho apresenta estímulos que requerem do trabalhador habilidades de adaptação (GENUINO, GOMES e MORAES, 2009).

Segundo os autores, os estressores organizacionais serão definidos de acordo com as respostas do indivíduo frente a eventos que lhe cause estresse, ou seja, para 
cada pessoa existem eventos específicos de gatilho, sendo que, enquanto para um o excesso de trabalho pode ser algo positivo e estimulante, para outra pessoa, pode ser visto como algo negativo que afeta a vida pessoal e profissional.

\section{Síndrome de Burnout e a relação com a Psicologia da Saúde}

A palavra Burnout tem origem inglesa e para Trigo et al., (2007) significa "aquilo que deixou de funcionar por absoluta falta de energia" (p. 225). Para Cândido, Souza (2017) significa que "o indivíduo chegou ao seu limite, sente-se esgotado fisica e emocionalmente" (p. 2). Para esses autores, existe uma explicação simples para identificação da Síndrome de Burnout (SB) nos índivíduos: trata-se de um alto grau de estresse, que afeta tanto o lado físico e emocional e que tem que estar diretamente relacionado às condições de ambiente de trabalho (TRIGO et al,. 2007; CÂNDIDO, SOUZA, 2017).

Do ponto de vista psicológico, o estresse é entendido como resultado de uma demanda provocada pelo meio interno ou externo, percebido como ameaçador, desagradável ou aversivo, responsável por produzir uma resposta psicofisiológica com efeitos sobre o indivíduo. Os estressores, por sua vez, são circunstâncias ou eventos que representam uma ameaça a uma meta importante (integridade física ou bem-estar psicológico) e que exigem a adaptação a uma nova condição.

Contudo o estresse não deve ser definido apenas como a resposta biológica do organismo. Ele envolve ainda mecanismos de apreciação psicológica que são determinantes nas respostas emocionais e comportamentais aos eventos estressores (CASTRO, 2018). O alto nível de estresse e de fatores estressantes desecadeiam a SB. Essa síndrome é muito pesquisada nas investigações feitas sobre o estresse em decorrência do trabalho e acontece quando o indivíduo faz várias investidas para enfrentar-lo (OLIVEIRA; BARGADI, 2009).

A SB é reconhecida e registrada na Classificação Estatística Internacional de Doenças e Problemas Relacionados à Saúde sob o código CID II (BRASIL, 2018). Cândido e Souza (2017) reforçam que a legislação brasileira relaciona-a "ao auxílio doença ao trabalhador como uma condição causada no ou pelo ambiente de 
trabalho ou doença ocupacional” (p. 5).

É necessário tratar a doença SB e observar os primeiros sinais e sintomas antes que se torne muito grave (prevenção primária). Crises de depressão, ansiedade, fadiga, irritação, hostilidade e falta de motivação são considerados sintomas da SB. As situações do cotidiano dos policiais são extremamentes estressoras e devem ser avaliadas para buscar o tratamento assim que perceba os primeiros sintomas (SILVA, SALLES, 2016).

A criação de uma escala diagnóstica o Maslach Burnout Inventory (MBI), padrão-ouro para detecção da síndrome permitiu o desenvolvimento da pesquisa epidemiológica do Burnout (BRASIL, 2018). Esse instrumento contribui de forma positiva na identificação dos casos, seu grau de comprometimento, incidência e prevalência de casos (VIEIRA; RUSSO, 2019).

Há, na atualidade, muitos estudos desenvolvidos sobre o estresse na carreira do policial militar, sendo assim, dentre os já existentes é enfatizado que o policial militar, que trabalha em meio ostensivo, é vulnerável ao estresse (OLIVEIRA; BARGADI, 2009).

A SB é decorrente de agravos e doenças de ordem fisiológica, emocionais e comportamentais. As fisiológicas são as dores musculares, no sistema digestivo e nervoso e até mesmo as disfunções sexuais; as emocionais são de origem depressiva, ansiedade, baixa autoestima, distanciamento emocional entre outros; e por fim, as comportamentais, geralmente as que mais afetam o rendimento no trabalho, pois referem-se à queda de produtividade, abandono do emprego, absenteísmo, uso de drogas lícitas e ilícitas, agressividade com os colegas de trabalho e do próprio convívio. (CARVALHO, 2019).

Seguindo a linha de pesquisa de Sartori, Cassandre e Varcesi (2008), a partir da verificação da existência do Burnout em policiais, observou-se que "os fatores estresssantes a que esse grupo é submetido leva a exaustão emocional desencadeando a SB” (p. 4).

Dentre as desordens associadas ao trabalho, especificamente no âmbito da saúde mental, destacam-se os estudos sobre o estresse e doenças comórbidas (como depressão, transtornos de ansiedade) e/ou contíguas a este, como a SB. 
Nos estudos de Maslach (1978) apud Carvalho (2019), a SB, geralmente considerada um problema social que é desencadeado no ambiente de trabalho, compreende um conjunto de três variáveis associadas: exaustão emocional (EE), a despersonalização (D) e a diminunição da realização pessoal (DRP). Os indivíduos que já apresentam a EE após o diagnóstico são afetados o físico e emocional em seu ambiente de trabalho, e os sintomas mais comuns são dor lombar e cansaço (SUDA, COELHO, BERTACI, SANTOS, 20II)

O esgotamento emocional supõe sintomas de perda de energia, esgotamento físico e psíquico, e uma sensação de ter chegado ao limite, ou seja, de não aguentar mais. A pessoa encontra-se anulada, incapacitada para dar algo de si. É fácil relacionar esses sintomas com a depressão. A abulia (falta de vontade e iniciativa), a anedonia (incapacidade de experimentar prazer) e a apatia (falta de motivação ou entusiasmo) tomam conta do sujeito. além desses, a despersonalização que consiste em viver o trabalho como algo alheio e estranho, refere-se na baixa realização pessoal, e se relaciona com a sensação de ser inadequado à profissão exercida. São sentimentos de incapacidade e baixa autoestima com relação ao que se faz (CARVALHO, 2019).

De acordo com o autor acima, podemos então entender como a $\mathrm{SB}$, se não evitada e prevenida a tempo, pode desencadear situações adversas negativas que perduram por muito mais tempo que se espera e também podem levar o indívido ao pensamento suicida.

Dessa forma, faz-se necessário analisar a questão apresentada por Abreu (2002), quando se refere ao fato de que Burnout não é exatamente a exaustão emocional, e sim, o efeito de resultados repetitivos de tentativas frustantes de conviver e lidar com fatores estressores no ambiente de trabalho, desencadeando o esgotamento fisico e psicológico do sujeito. Essa concepção reforça a importância no investimento de estudos na área da psicologia. Sendo que ela tem seu foco na relação da interação que o sujeito estabelece com o meio e como isso influencia em seu comportamento profissional e social.

Para Firme, Alves e Roque (2007), destaca-se "o esgotamento emocional, a despersonalização, a diminuição das conquistas pessoais e a autoavaliação como um ente negativo no ambiente de trabalho" (p. 26). E, ainda acrescentam que a SB pode 
desencadear o desenvolvimento da Síndrome do Esgotamento Profissional, que apresenta praticamente os mesmos sintomas citados na SB. Acrescenta-se, ainda que, "uma grande exaustão, indiferença ou frieza, falta de autoestima, cefaléia, distúrbios gastro-intestinais, insônia e ainda dificuldades respiratórias” (FIRME, ALVES, ROQUE, 2007, p. 3i).

$\mathrm{Na}$ área da psicologia, as concepções teóricas sobre a perspectiva da SB têm foco, especialmente na Concepção Clínica, ou seja, nessa perspectiva, Burnout é caracterizada como um conjunto que desencadeia no profissional uma depressão muito forte que pode culminar em suicídio (ROSSETTI, et al, 2008).

A Psicologia da Saúde Ocupacional aplica os conhecimentos científicos para melhorar a qualidade da vida profissional e melhorar a segurança, a saúde e o bemestar dos trabalhadores em todas as profissões (CASTRO, 2018).

Cumpre salientar a identificação do problema da pesquisa: associação entre as condições de trabalho, fatores de risco para adoecimento e as influências negativas observadas no comportamento de policiais militares, identificadas como alguns dos sintomas relacionados à $\mathrm{SB}$.

Identificados os fatores de risco, a ênfase passa a ser referência dos autores, relacionados à prevenção primária e secundária como proposta de intervenção. A partir da revisão da literatura buscou-se identificar: quais as causas e consequências geradas por elementos estressores, presentes na rotina de policiais militares e, quais as propostas de prevenção estão destacadas em resultados de pesquisas publicadas na última década.

\subsection{Objetivos}

I.3.I Objetivo Geral

Analisar as principais causas e consequências dos elementos estressores no cotidiano de trabalho em policiais militares, apontadas em resultados de pesquisas publicadas na última década.

I.3.2 Objetivos específicos

- Identificar quais fatores estressores corroboram para aumentar os níveis de estresse dos policiais.

- Investigar quais os sinais e sintomas relacionados ao estresse ocupacional e a correlação com a Síndrome de Burnout (SB). 
- Caracterizar propostas de prevenção primaria e/ou secundária identificadas nos estudos publicados.

\section{I.4 Justificativa}

Risco de vida, situações de alto nível de estresse, alerta constante de perigo, opinião pública desfavorável, risco de acidentes com suas ferramentas de trabalho, pressão exercida pela população, são algumas das dificuldades encontradas diariamente pelos policiais militares. Esses são alguns dos fatores que elevam os riscos de estresse que provocam ou contribuem para desencadear a SB.

A definição por uma revisão bibliográfica que possibilitasse a construção de banco de dados para analisar, em estudos publicados, os fatores observados na rotina de políciais. Identificados esses fatores, faz-se necessário averiguar, se são apontadas propostas de prevensão primárias ou secundárias nos resultados das pesquisas publicadas. Aprofundar estudos na área apresenta relevância profissional e social, tendo em vista que uma das propostas da psicologia é, justamente, contribuir para minimizar as situações de enfrentamento do sujeito nas condições do ambiente de trabalho.

\section{MÉTODO}

2.I Análises da Unidade

O método escolhido para este estudo foi da pesquisa bibliográfica, configurando um Projeto teórico e documental. Conforme esclarece Boccato (2006), a pesquisa bibliográfica busca "a resolução de um problema (hipótese), por meio de referenciais teóricos publicados, analisando e discutindo as várias contribuições científicas" (p. 266). Esse tipo de pesquisa trará subsídios para o conhecimento sobre o que foi pesquisado. A seguir, é descrito o processo de seleção de amostra (Fig. oı). 


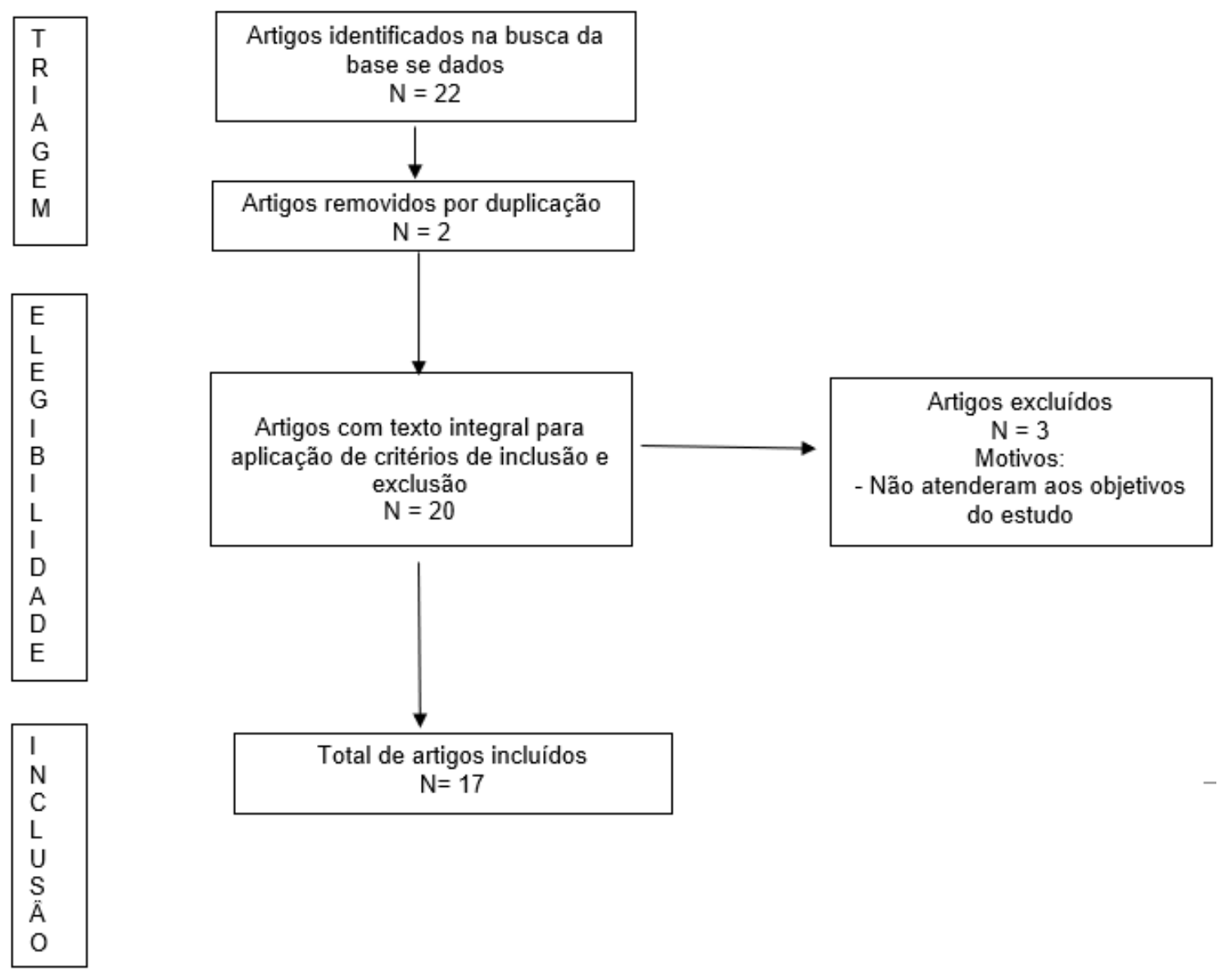

\section{Figura or: Processo de seleção de amostra}

\section{Fonte: Autores da pesquisa.}

2.2 Procedimentos para coleta de dados

A metodologia utilizada na revisão bibliográfica (FERENHOF, FERNANDES, 2016), partiu das contribuições da abordagem qualitativa dos dados pesquisados e da proposta de ampliar os conhecimentos sobre o adoecimento do policial militar, relacionado ao estresse na rotina de trabalho - Síndrome de Burnout (SB).

De acordo Zappellomo e Feuerschutte (2015), a maioria dos autores relaciona suas definições de procedimento metodológico às formas como os dados são coletados e analisados, caracterizando dessa forma a combinação de técnicas ou métodos.

Inicialmente, foi realizada coleta de artigos e publicações nas bases de dados Scientific Electronic Library Online (SCiELO), Periódicos Eletrônicos em Psicologia (PePsic), Biblioteca Virtual em Saúde - Psicologia (BVS-Psi), Literatura Latino- 
Americana e do Caribe em Ciências da Saúde (LILACS, Livros eletrônicos na SCRIBD e outras publicações, utilizando como descritores: a) estresse no ambiente de trabalho e saúde mental, b) Síndrome de Burnout, c) estresse no ambiente de trabalho de policiais.

Após a triagem dos artigos, foram selecionadas 22 publicações. Os critérios de inclusão foram: a) fidelidade ao tema; b) ano de publicação (2009 - 2019), c) publicações de estudos originais, realizados no Brasil.

Os critérios de exclusão foram: a) duplicidade (o2) de publicações; b) não atender aos objetivos da pesquisa (03), perfazendo um total de 16 artigos e or tese.

No que se refere à metodologia utilizada nesses estudos, foi possível identificar 03 revisões da literatura e i4 estudos transversais. Cabe destacar a escassez de publicações na área, nos últimos ıo anos.

\subsection{Procedimentos para análise dos dados}

Os dados coletados para posterior análise foram discriminados no Quadro or, para maior visibilidade e para facilitar a categorização e análise comparativa entre: autor/ ano; fatores estressores; sinais e sintomas; assim como, propostas de prevenção presentes nas publicações selecionadas para análise sobre o tema.

\section{RESULTADOS}

Quadro or - Tratamento dos Dados - Revisão de Literatura

\begin{tabular}{|c|c|c|c|c|}
\hline $\begin{array}{l}\text { (Autores } \\
\text { e ano) }\end{array}$ & $\begin{array}{l}\text { Tipo de } \\
\text { Estudo }\end{array}$ & Fatores Estressores & Sinais e sintomas & $\begin{array}{l}\text { Propostas de } \\
\text { prevenção e } \\
\text { intervenção }\end{array}$ \\
\hline $\begin{array}{l}\text { or } \\
\text { Castro et } \\
\text { al., } 2019\end{array}$ & $\begin{array}{l}\text { Revisão } \\
\text { da } \\
\text { literatura }\end{array}$ & $\begin{array}{l}\text { Condições e } \\
\text { ambiente de } \\
\text { trabalho; Carga } \\
\text { psicológica } \\
\text { enfrentadas na } \\
\text { rotina de controle e } \\
\text { prevenção da } \\
\text { violência. Percepção } \\
\text { do risco de morte } \\
\text { eminente }\end{array}$ & $\begin{array}{l}\text { Problemas } \\
\text { musculoesqueléticos } \\
\text { Transtornos mentais } \\
\text { Estresse pós- } \\
\text { traumático } \\
\text { Síndrome de Burnout. } \\
\text { Afastamentos longos, } \\
\text { reincidência com } \\
\text { maiores níveis de } \\
\text { incapacidade. }\end{array}$ & $\begin{array}{l}\text { Não é } \\
\text { evidenciada } \\
\text { nenhuma forma } \\
\text { de prevenção } \\
\text { primária ou } \\
\text { secundária como } \\
\text { proposta } \\
\text { interventiva. }\end{array}$ \\
\hline $\begin{array}{l}02 \\
\text { Urbani et } \\
\text { al., } 2019\end{array}$ & $\begin{array}{l}\text { Revisão } \\
\text { da } \\
\text { Literatura }\end{array}$ & $\begin{array}{l}\text { Desvalorização } \\
\text { profissional } \\
\text { Comprometimento } \\
\text { da QVT - }\end{array}$ & $\begin{array}{l}\text { Relação entre o } \\
\text { estresse e DTM } \\
\text { (síndrome cujo } \\
\text { portador pode }\end{array}$ & $\begin{array}{l}\text { Proposta } \\
\text { interventiva: } \\
\text { Paciente avaliado } \\
\text { e deve ser }\end{array}$ \\
\hline
\end{tabular}




\begin{tabular}{|c|c|c|c|c|}
\hline & & $\begin{array}{l}\text { Qualidade de Vida } \\
\text { no Trabalho; } \\
\text { Relação entre o } \\
\text { estresse e o risco de } \\
\text { desenvolvimento da } \\
\text { DTM } \\
\text {. }\end{array}$ & $\begin{array}{l}\text { apresentar desde } \\
\text { simples incômodos } \\
\text { até sintomas } \\
\text { dolorosos), } \\
\text { Bruxismo; dor crônica. } \\
\text { Depressão, distúrbio } \\
\text { do sono, problemas } \\
\text { psiquiátricos e } \\
\text { ansiedade. }\end{array}$ & $\begin{array}{l}\text { assistido tratado } \\
\text { por equipe } \\
\text { multidisciplinar: } \\
\text { dentista, } \\
\text { psicólogos, } \\
\text { fonoaudiólogos, } \\
\text { fisioterapeutas e } \\
\text { neurologistas. }\end{array}$ \\
\hline $\begin{array}{l}03 \\
\text { Chaves, } \\
\text { Shimizu } \\
2018\end{array}$ & $\begin{array}{l}\text { Estudo } \\
\text { Transvers } \\
\text { al }\end{array}$ & $\begin{array}{l}\text { Exaustão e desgaste } \\
\text { emocional gerado } \\
\text { pelas ações e no } \\
\text { próprio ambiente } \\
\text { Despersonalização } \\
\text { A correlação entre o } \\
\text { estresse e a } \\
\text { qualidade do sono } \\
\text { em policiais. }\end{array}$ & $\begin{array}{l}\text { Sonolência diurna } \\
\text { durante o dia de } \\
\text { trabalho; Má qualidade } \\
\text { de sono, exaustão } \\
\text { emocional e } \\
\text { despersonalização. }\end{array}$ & $\begin{array}{l}\text { Proposta } \\
\text { interventiva: } \\
\text { Implantação de } \\
\text { medidas } \\
\text { institucionais nos } \\
\text { batalhões de } \\
\text { polícia militar e } \\
\text { programas que } \\
\text { incluam o } \\
\text { controle do } \\
\text { estresse. }\end{array}$ \\
\hline $\begin{array}{l}04 \\
\text { Lima et } \\
\text { al., } 2018\end{array}$ & $\begin{array}{l}\text { Estudo } \\
\text { Transvers } \\
\text { al }\end{array}$ & $\begin{array}{l}\text { O estresse no } \\
\text { ambiente de } \\
\text { trabalho; } \\
\text { Dupla jornada de } \\
\text { trabalho; } \\
\text { Dificuldade de } \\
\text { conciliar trabalho e } \\
\text { rotina familiar } \\
\text { Cobranças que } \\
\text { geram frustação e } \\
\text { baixa estima. }\end{array}$ & $\begin{array}{l}\text { Sintomas relacionados } \\
\text { à Síndrome de Burnout } \\
\text { verificada com maior } \\
\text { incidência em policiais } \\
\text { do sexo feminino (fase } \\
\text { inicial) do que do } \\
\text { masculino (fase de } \\
\text { alerta). Preocupação } \\
\text { excessiva com família. }\end{array}$ & $\begin{array}{l}\text { Prevenção } \\
\text { primária: } \\
\text { melhora } \\
\text { psicológica } \\
\text { proporcionada } \\
\text { pela prática do } \\
\text { exercício físico } \\
\text { apesar de não ter } \\
\text { evitado o } \\
\text { aparecimento da } \\
\text { Síndrome de } \\
\text { Burnout. }\end{array}$ \\
\hline $\begin{array}{l}05 \\
\text { Pelegrine } \\
\text { et al. } 2018\end{array}$ & $\begin{array}{l}\text { Estudo } \\
\text { Transvers } \\
\text { al }\end{array}$ & $\begin{array}{l}\text { Estresse } \\
\text { ocupacional; } \\
\text { Condições de } \\
\text { trabalho; } \\
\text { Visão negativa em } \\
\text { relação à } \\
\text { remuneração e } \\
\text { benéficos } \\
\text { Ambiente que gera } \\
\text { altos índices de } \\
\text { desgastes e } \\
\text { adoecimento; } \\
\text { Baixo apoio social. }\end{array}$ & $\begin{array}{l}\text { Insatisfação pessoal e } \\
\text { profissional gerando } \\
\text { desmotivação; } \\
\text { Sintomas físicos e } \\
\text { psicológicos; } \\
\text { Sensação de exaustão. }\end{array}$ & $\begin{array}{l}\text { Proposta } \\
\text { Interventiva: } \\
\text { Necessidade de } \\
\text { investimento do } \\
\text { Estado e em } \\
\text { equipamentos } \\
\text { mais eficientes; } \\
\text { Programa de } \\
\text { ncentivos e } \\
\text { valorização. }\end{array}$ \\
\hline 06 & Estudo & Rotinas estressantes & Incapacidade de "se & Proposta \\
\hline
\end{tabular}




\begin{tabular}{|c|c|c|c|c|}
\hline $\begin{array}{l}\text { Tavares } \\
\text { et al., } \\
2017\end{array}$ & $\begin{array}{l}\text { Transvers } \\
\text { al }\end{array}$ & $\begin{array}{l}\text { de trabalho; } \\
\text { Altos índices de } \\
\text { estresse na relação de } \\
\text { desenvolvimento de } \\
\text { Síndromes }\end{array}$ & $\begin{array}{l}\text { desligar" dos } \\
\text { problemas enfrentados } \\
\text { na rotina de trabalho; } \\
\text { Constante estado de } \\
\text { alerta e consequente } \\
\text { exaustão. } \\
\text { Alteração nos níveis de } \\
\text { cortisol }\end{array}$ & $\begin{array}{l}\text { interventiva } \\
\text { Necessidade de } \\
\text { estudos em } \\
\text { práticas de saúde } \\
\text { do trabalhador. } \\
\text { Avaliação sobre } \\
\text { níveis de cortisol } \\
\text { em policiais } \\
\text { militares e na } \\
\text { alteração na } \\
\text { saúde. }\end{array}$ \\
\hline $\begin{array}{l}07 \\
\text { Cândido } \\
\text { e Souza } \\
2017\end{array}$ & $\begin{array}{l}\text { Revisão } \\
\text { da } \\
\text { Literatura }\end{array}$ & $\begin{array}{l}\text { Número insuficiente } \\
\text { de profissionais } \\
\text { Trabalho noturno } \\
\text { Extensa jornada de } \\
\text { trabalho } \\
\text { Falta de estrutura } \\
\text { Mudanças } \\
\text { tecnológicas } \\
\text { Falta de } \\
\text { investimentos na } \\
\text { área: ferramentas, } \\
\text { logística e } \\
\text { especialização. }\end{array}$ & $\begin{array}{l}\text { Estafa,; problemas } \\
\text { cardíacos, pressão alta } \\
\text { Agravamento de } \\
\text { sintomas antes } \\
\text { considerados } \\
\text { moderados } \\
\text { Abuso de álcool ou } \\
\text { drogas } \\
\text { Alergias } \\
\text { Falta de apetite sexual } \\
\text { Apatia e fadiga }\end{array}$ & $\begin{array}{l}\text { Proposta } \\
\text { interventiva } \\
\text { Técnicas } \\
\text { terapêuticas } \\
\text { Exercícios } \\
\text { físicos ara } \\
\text { liberação de beta } \\
\text { endorfina. }\end{array}$ \\
\hline $\begin{array}{l}\text { o8 } \\
\text { Silva, } \\
\text { Salles, } \\
2016\end{array}$ & $\begin{array}{l}\text { Estudo } \\
\text { Transvers } \\
\text { al }\end{array}$ & $\begin{array}{l}\text { Estresse } \\
\text { ocupacional. } \\
\text { Dificuldade de } \\
\text { colaboradores de } \\
\text { enfrentar as } \\
\text { exigências do } \\
\text { trabalho } \\
\text {-Influência do } \\
\text { estresse do trabalho } \\
\text { na vida particular. }\end{array}$ & $\begin{array}{l}\text { Influência negativa no } \\
\text { comportamento. } \\
\text { Desgaste físico e } \\
\text { psicológico. }\end{array}$ & $\begin{array}{l}\text { Formas } \\
\text { alternativas de } \\
\text { tratamento para } \\
\text { melhorar a } \\
\text { qualidade de vida } \\
\text { dos } \\
\text { trabalhadores. o } \\
\text { desempenho e } \\
\text { produtividade. } \\
\text { Prevenção } \\
\text { secundária. }\end{array}$ \\
\hline $\begin{array}{l}\text { o9 } \\
\text { Liz et al., } \\
2014\end{array}$ & $\begin{array}{l}\text { Estudo } \\
\text { transversa } \\
1\end{array}$ & $\begin{array}{l}\text { Evento traumático } \\
\text { na carreira como } \\
\text { parte da } \\
\text { rotina do policial. } \\
\text { Atividades que } \\
\text { geram estresse e } \\
\text { exaustão. } \\
\text { Policiais femininas } \\
\text { que atuam na área } \\
\text { operacional } \\
\text { Estão mais sujeitas }\end{array}$ & $\begin{array}{l}\text { Alto índice de IEP - } \\
\text { Índice de Estresse } \\
\text { Percebido - entre } \\
\text { policiais com menos de } \\
35 \text { anos: } \\
\text { má qualidade do sono, } \\
\text { maior IEP foi } \\
\text { identificado em } \\
\text { policiais que já } \\
\text { passaram por algum } \\
\text { evento de situações }\end{array}$ & $\begin{array}{l}\text { Proposta } \\
\text { interventiva: } \\
\text { Estudos sobre } \\
\text { intervenções } \\
\text { visando o } \\
\text { controle e/ou } \\
\text { prevenção do } \\
\text { estresse em } \\
\text { policiais } \\
\text { militares nos } \\
\text { batalhões - IEP.. }\end{array}$ \\
\hline
\end{tabular}




\begin{tabular}{|c|c|c|c|c|}
\hline & & $\begin{array}{l}\text { ao IEP } \\
\text { do que as que atuam } \\
\text { na área } \\
\text { administrativa. }\end{array}$ & traumáticas. & \\
\hline $\begin{array}{l}\text { Io } \\
\text { Bezerra } \\
\text { et al., } \\
2013\end{array}$ & $\begin{array}{l}\text { Estudo } \\
\text { Transvers } \\
\text { al }\end{array}$ & $\begin{array}{l}\text { Discriminação de } \\
\text { gênero percebido } \\
\text { como importante } \\
\text { fator estressante. } \\
\text { O relacionamento } \\
\text { familiar é afetado } \\
\text { pelo estresse no } \\
\text { trabalho. } \\
\text { Preconceito, } \\
\text { discriminação de } \\
\text { gênero. .Diferenças } \\
\text { na distribuição das } \\
\text { atividades, e } \\
\text { desconfiança dos } \\
\text { homens em relação à } \\
\text { capacidade feminina }\end{array}$ & $\begin{array}{l}\text { Sofrimento psíquico } \\
\text { aparece mais } \\
\text { fortemente } \\
\text { entre as oficiais com } \\
\text { cargos de chefia } \\
\text { Estresse que geram } \\
\text { vários sintomas com } \\
\text { consequências } \\
\text { negativas no } \\
\text { relacionamento } \\
\text { familiar. }\end{array}$ & $\begin{array}{l}\text { Proposta } \\
\text { Interventiva: o } \\
\text { prática de } \\
\text { esportes, } \\
\text { modalidades de } \\
\text { relaxamento. } \\
\text { Incentivo a } \\
\text { consultas } \\
\text { médicas } \\
\text { regulares, boa } \\
\text { alimentação } \\
\text { como estratégias } \\
\text { para amenizar ou } \\
\text { prevenir as } \\
\text { consequências do } \\
\text { estresse entre } \\
\text { policiais } \\
\text { femininas. }\end{array}$ \\
\hline $\begin{array}{l}\text { An } \\
\text { And rol }\end{array}$ & $\begin{array}{l}\text { Estudo } \\
\text { Transvers } \\
\text { al }\end{array}$ & $\begin{array}{l}\text { Alta exposição a } \\
\text { diferentes fatores de } \\
\text { risco que podem } \\
\text { afetar sua saúde } \\
\text { física e mental, bem } \\
\text { a QVP: fatores } \\
\text { físicos, ergonômicos, } \\
\text { acidentes, } \\
\text { organização do } \\
\text { trabalho e fatores } \\
\text { psicossociais de } \\
\text { risco; } \\
\text { Identificação de } \\
\text { baixos níveis de } \\
\text { Hardiness em } \\
\text { policiais militares e } \\
\text { a diferença de } \\
\text { gênero em relação ao } \\
\text { estresse }\end{array}$ & $\begin{array}{l}\text { Identificação de baixos } \\
\text { níveis de Hardiness em } \\
\text { policiais militares e a } \\
\text { relação dos sintomas } \\
\text { com o estresse no } \\
\text { ambiente de trabalho. } \\
\text { Adoecimento de } \\
\text { profissionais. } \\
\text { Menor nível Hardiness } \\
\text { (Compromisso, } \\
\text { Controle e Desafio), } \\
\text { relacionado ao maior } \\
\text { nível de estresse. }\end{array}$ & $\begin{array}{l}\text { Proposta } \\
\text { interventiva } \\
\text { Propostas de } \\
\text { análise aos } \\
\text { fatores que } \\
\text { interferem na } \\
\text { QVP da policia } \\
\text { militar, } \\
\text { observando a } \\
\text { questão de } \\
\text { gênero e o } \\
\text { desenvolvimento } \\
\text { de programas } \\
\text { que tragam } \\
\text { melhor qualidade } \\
\text { no trabalho e nas } \\
\text { relações } \\
\text { interpessoais. }\end{array}$ \\
\hline $\begin{array}{l}\text { I2 } \\
\text { Souza et } \\
\text { al., } 2012\end{array}$ & $\begin{array}{l}\text { Estudo } \\
\text { Transvers } \\
\text { al }\end{array}$ & $\begin{array}{l}\text { Estresse } \\
\text { ocupacional. } \\
\text { Exigência do } \\
\text { trabalho e a } \\
\text { dificuldade de }\end{array}$ & $\begin{array}{l}\text { Embora o estresse } \\
\text { tenha origem } \\
\text { psicológica afeta a } \\
\text { saúde física. } \\
\text { Sofrimento psíquico }\end{array}$ & $\begin{array}{l}\text { Prevenção } \\
\text { primária } \\
\text { Atividades física. } \\
\text { Prevenção } \\
\text { secundária }\end{array}$ \\
\hline
\end{tabular}




\begin{tabular}{|c|c|c|c|c|}
\hline & & $\begin{array}{l}\text { conciliar com a vida } \\
\text { particular. } \\
\text { Desvalorização } \\
\text { pessoal e } \\
\text { profissional. }\end{array}$ & Ansiedade e depressão & $\begin{array}{l}\text { tratamento } \\
\text { :medicamentoso, } \\
\text { terapias e } \\
\text { acupuntura. }\end{array}$ \\
\hline $\begin{array}{l}13 \\
\text { Ferreira } \\
\text { et al., } \\
2012\end{array}$ & $\begin{array}{l}\text { Estudo } \\
\text { Transvers } \\
\text { al }\end{array}$ & $\begin{array}{l}\text { Aspectos negativos } \\
\text { relacionados ao } \\
\text { ambiente e } \\
\text { condições de } \\
\text { trabalho: trabalho } \\
\text { repetitivo, ritmo de } \\
\text { trabalho acelerado, } \\
\text { esforço físico } \\
\text { excessivo, pouca } \\
\text { liberdade de decisão. } \\
\text { Falta de suporte dos } \\
\text { superiores, inclusive } \\
\text { entre colegas de } \\
\text { trabalho. }\end{array}$ & $\begin{array}{l}\text { Sintomas relacionados } \\
\text { ao sofrimento } \\
\text { psíquicos e doenças } \\
\text { físicas. } \\
\text { Verificou-se que mais } \\
\text { da metade dos policiais } \\
\text { estão insatisfeitos ou } \\
\text { que gera, o longo do } \\
\text { tempo, perda da QVT, } \\
\text { insatisfação e } \\
\text { depressão. }\end{array}$ & $\begin{array}{l}\text { Proposta } \\
\text { interventiva } \\
\text { Sugere-se a } \\
\text { utilização de } \\
\text { estratégias que } \\
\text { promovam maior } \\
\text { integração social } \\
\text { e cooperação } \\
\text { entre os } \\
\text { necessidades de } \\
\text { estudos na área } \\
\text { para prevenção } \\
\text { de agravos á } \\
\text { saúde. }\end{array}$ \\
\hline $\begin{array}{l}\text { I4 } \\
\text { Minayo } \\
\text { et al., 20II }\end{array}$ & $\begin{array}{l}\text { Estudo } \\
\text { Transvers } \\
\text { al }\end{array}$ & $\begin{array}{l}\text { Precária frequência } \\
\text { de atividade física } \\
\text { Problemas que } \\
\text { geram a necessidade } \\
\text { de mudanças nas } \\
\text { dimensões } \\
\text { individual } \\
\text { e profissional. }\end{array}$ & $\begin{array}{l}\text { Elevada frequência } \\
\text { de sofrimento psíquico } \\
\text { (SRQ-2o). } \\
\text { Aumento da prática de } \\
\text { violência domestica } \\
\text { Desordem pós- } \\
\text { traumática } \\
\text { Abuso de drogas licita } \\
\text { e ilícitas } \\
\text { Sobrepeso e obesidade } \\
\text { Taxas de suicídio }\end{array}$ & $\begin{array}{l}\text { Não há indicação } \\
\text { de ações } \\
\text { preventivas nos } \\
\text { trabalhos } \\
\text { analisados. Mas } \\
\text { os autores } \\
\text { reconhecem a } \\
\text { necessidade de } \\
\text { ações } \\
\text { interventivas, } \\
\text { inclusive } \\
\text { traçados em } \\
\text { conjunto com os } \\
\text { próprios } \\
\text { policiais. }\end{array}$ \\
\hline $\begin{array}{l}\text { I5 } \\
\text { Oliveira } \\
\text { e Santos } \\
2010\end{array}$ & $\begin{array}{l}\text { Estudo } \\
\text { Transvers } \\
\text { al }\end{array}$ & $\begin{array}{l}\text { Constante estado de } \\
\text { alerta } \\
\text { Enfrentamento em } \\
\text { situações de tática } \\
\text { nas ruas } \\
\text { Dever de prontidão } \\
\text { para desenvolver } \\
\text { atividades sem poder } \\
\text { se abster, mesmo } \\
\text { que causem } \\
\text { situações de } \\
\text { conflitos ideológicos }\end{array}$ & $\begin{array}{l}\text { Profissionais Cansados } \\
\text { emocionalmente } \\
\text { Agir com } \\
\text { Impulsividade } \\
\text { Desequilíbrio } \\
\text { emocional } \\
\text { Constante estado de } \\
\text { insatisfação } \\
\text { Agressividade } \\
\text { Pensamento de } \\
\text { suicídio. }\end{array}$ & $\begin{array}{l}\text { A maioria das } \\
\text { corporações não } \\
\text { mantém suporte } \\
\text { clinico e } \\
\text { psicológico para } \\
\text { conter os } \\
\text { sintomas latentes } \\
\text { já no inicio o que } \\
\text { significa que não } \\
\text { há estratégias } \\
\text { nem de } \\
\text { prevenção }\end{array}$ \\
\hline
\end{tabular}




\begin{tabular}{|c|c|c|c|c|}
\hline & & e/ou pessoais. & & $\begin{array}{l}\text { primárias; } \\
\text { Prevenções } \\
\text { secundárias: o } \\
\text { profissional é } \\
\text { afastado para } \\
\text { tratamento. }\end{array}$ \\
\hline $\begin{array}{l}\text { I6 } \\
\text { Dantas et } \\
\text { al., 2010 }\end{array}$ & $\begin{array}{l}\text { Estudo } \\
\text { Transvers } \\
\text { al }\end{array}$ & $\begin{array}{l}\text { Utilização do } \\
\text { Inventário de } \\
\text { Sintomas de Stress } \\
\text { para Adultos de Lipp } \\
\text { (ISSL). } \\
\text { Alto nível de } \\
\text { estresse, com } \\
\text { predominância da } \\
\text { fase de resistência. } \\
\text { Profissionais do } \\
\text { sexo feminino } \\
\text { predomina mais } \\
\text { grau de estresse. } \\
\text { Dupla jornada }\end{array}$ & $\begin{array}{l}\text { Sintomas de estresse } \\
\text { mais severos no gênero } \\
\text { feminino. } \\
\text { Sinais de exaustão e } \\
\text { quase exaustão (LIPP). } \\
\text { Aspectos que refletem } \\
\text { na saúde mental: foi } \\
\text { identificada com } \\
\text { sintomatologia de } \\
\text { estresse em mais da } \\
\text { metade do grupo. }\end{array}$ & $\begin{array}{l}\text { Proposta } \\
\text { interventiva : } \\
\text { adotar } \\
\text { tratamentos } \\
\text { capazes melhorar } \\
\text { a resistência e } \\
\text { aliviar os } \\
\text { sintomas } \\
\text { (alimentação } \\
\text { adequada, } \\
\text { exercícios de } \\
\text { relaxamento e } \\
\text { respiração, } \\
\text { atividade física). }\end{array}$ \\
\hline $\begin{array}{l}\text { I7 } \\
\text { Oliveira, } \\
\text { Bargodi, } \\
2009\end{array}$ & $\begin{array}{l}\text { Estudo } \\
\text { Transvers } \\
\text { al }\end{array}$ & $\begin{array}{l}\text { Atividade militar se } \\
\text { insere em um } \\
\text { contexto de } \\
\text { vulnerabilidade e } \\
\text { indicam que, quanto } \\
\text { maior o risco } \\
\text { envolvido, menor é a } \\
\text { segurança em } \\
\text { relação à carreira. } \\
\text { Estresse e } \\
\text { relacionado ao grau } \\
\text { de severidade na } \\
\text { questão de gênero. } \\
\text { Vulnerabilidade }\end{array}$ & $\begin{array}{l}\text { Na aplicação do ISSL } \\
\text { determinou mais da } \\
\text { metade dos } \\
\text { participantes a } \\
\text { sintomatologia de } \\
\text { estresse (sexo } \\
\text { feminino), por } \\
\text { sintomas psicológicos } \\
\text { com níveis menores } \\
\text { nos aspectos físicos e } \\
\text { mais severos para } \\
\text { psicológicos } \\
\text { vulneráveis ao estresse } \\
\text { devido à dupla jornada. }\end{array}$ & $\begin{array}{l}\text { O estresse na } \\
\text { profissão de } \\
\text { policial militar é } \\
\text { algo muito } \\
\text { comum então } \\
\text { buscar } \\
\text { alternativas de } \\
\text { intervenção } \\
\text { constitui um } \\
\text { tema não só } \\
\text { relevante como } \\
\text { necessário a ser } \\
\text { desenvolvido e } \\
\text { pesquisado. }\end{array}$ \\
\hline
\end{tabular}

Fonte: Dados do estudo - adaptado pelos autores

A partir da seleção das publicações, realizada a partir dos descritores previamente definidos, buscou-se priorizar aqueles que trouxessem claramente fatores estressores nas condições e local de trabalho, sinais e sintomas de comprometimento físico ou psicológico relacionados ao esgotamento na Qualidade de Vida no Trabalho (QVT) (que se refere aos elementos relacionados ao ambiente) e Qualidade de Vida do Profissional (QVP) (que se refere à satisfação do profissional dos participantes de estudos empíricos). 
A proposta inicial foi, também, selecionar os que apresentassem algum tipo de prevenção primária ou secundária já realizada nas corporações, o que constituiu uma frustação tendo em vista a quantidade mínima (02) identificado nos artigos pesquisados. Em relação às propostas interventivas, foi possível observar um quantitativo considerável (15), já que aparece claramente nos resultados alguns tipos de programas, propostas como modelos para serem desenvolvidos visando minimizar a problemática.

Essa análise obedeceu ao modelo de categorização, destacando e agrupando os autores e suas concepções de acordo com as categorias: I) adoecimento e ambiente de trabalho; 2) indicadores para estresse (causa) relacionado ao Burnout; e 3) prevenção primárias e secundárias e propostas interventivas. A análise de dados coletados, a partir da categorização, traz uma forma de agrupamento de ideias afins e seus respectivos autores, a partir de estudo comparativo, tendo como referência do Quadro oI.

I) Adoecimento no ambiente de trabalho dos policiais

Segundo os dados do Quadro or, os autores concordam sobre a questão do adoecimento dos policiais no seu ambiente de trabalho. Esse adoecimento é visto por ações de exaustão, sobrecarga de trabalho e esforço físico, trabalho repetitivo, estresse com o trabalho em situações de rua, cansaço, esgotamento físico e emocional que os policiais relatam sofrerem no seu ambiente de trabalho (CHAVES, SHIMIZU 2018; ANDRADA 2013; FERREIRA et al., 2012; OLIVEIRA e SANTOS 2010).

Outro fator que devemos levar em consideração, por ser relevante, é a questão do gênero. As policiais femininas sofrem muito preconceito no seu ambiente de trabalho, pelos próprios colegas de profissão; além disso, precisam conciliar a dupla jornada de trabalho (família $\mathrm{x}$ filhos $\mathrm{x}$ trabalho), são mais emotivas e por isso mais vulneráveis em situações de risco no cotidiano da atividade policial que devem desempenhar. E, outros motivos, até mesmo fisiológicos, fazem com que o grau de estresse no sexo feminino seja considerado mais elevado do que nos policiais do sexo masculino (LIMA et al., 2018; DANTAS et al., 2010). 
2) Indicadores de estresses e sinais e sintomas relacionados à SB:

Os fatores estressores que indicam que os policiais estão sofrendo $\mathrm{SB}$, segundo os autores dessa pesquisa, são: a) medo, risco de morte e constante estado de alerta (CASTRO et al, 2019; OLIVEIRA E SANTOS, 2010); b) comprometimento do QVT e desenvolvimento do DTM (URBANI et al, 2019); c) desgaste, exaustão e rotina estressante (CHAVES, SHIMIZU, 2018; PELEGRINE et al, 2018; TAVARES et al, 2017); d) jornada dupla de trabalho e discriminação de gênero, dificuldade de conciliação entre a vida profissional e particular, as policiais podem sofrer IEP e alto nível de estresse e vulnerabilidade (LIMA et al, 2018; SILVA E SALLES, 2016; LIZ et al, 2014; BEZERRA et al, 2013; ANDRADE, 2013; SOUZA et al 2012; DANTAS et al, 2010, OLIVEIRA, BARGODI, 2009); e) falta de infraestrutura física, pessoal e material (CÃNDIDA E SOUZA, 2017; FERREIRA et al, 2012); e, por fim, podemos citar $f$ ) falta de preparo físico (MINAYO et al, 2oII).

Os sinais e sintomas mais comuns nesses casos são fadiga, comprovação do estágio de exaustão e quase exaustão (LIPP), bruxismo; dor crônica, depressão, pensamento suicida, distúrbio do sono, desordem pós-traumática, uso e abuso de drogas licita e ilícitas, sobrepeso e obesidade, insatisfação pessoal, alterações psiquiátricas como ansiedade entre outros. (CASTRO et al, 2019; CÂNDIDO E SOUZA, 2017).

3) Prevenções primárias e secundárias e propostas interventivas.

Como podemos observar no Quadro or, a prevenção primária nos casos de SB em policiais é vista como de difícil intervenção, pois geralmente quando os sinais e sintomas aparecem, o quadro encontra-se mais evoluído. Para isso, sugere-se que os policiais sejam acompanhados por equipe multidisciplinar, para que possam realizar atividades físicas com regularidade, e para que trabalhem o corpo e a mente, com o intuito de buscar uma melhor qualidade de vida em seu ambiente de trabalho (URBANI, et al, 2019; FERREIRA et al, 2012).

Para a prevenção secundária, após o diagnóstico efetivo da $\mathrm{SB}$, alguns autores sugerem: a) tratamento psiquiátrico, terapia, medicação e afastamento (SOUZA, et al, 2012; DANTAS et al, 2010); b) assistência da equipe multidisciplinar para acompanhar o policial no tratamento (URBANI, et al, 2019); c) analisar os fatores que interferem na QVT dos policiais e medidas institucionais como proposta de minimizar esse agravo à 
saúde do policial (CHAVES, SHIMIZU, 2019; PELEGRINE et al 2018); d) prática de atividades físicas (LIMA et al, 2018); CÂNDIDO, SOUZA, 2017; BEZERRA et al 2013); e) além de mais estudos sobre a prática de saúde relacionados a essa temática (TAVARES et al, 2017; FERREIRA et al, 2012; MINAYO et al, 20II).

\section{DISCUSSÕES}

A Psicologia da Saúde Ocupacional é uma área da psicologia responsável por estudar os agravos à saúde do profissional, independente de sua profissão. No caso dos policiais, a SB, além de interferir na QVT do policial pode desencadear problemas mais graves, interferindo na sua vida profissional e pessoal, como é o caso da depressão e pensamento suícida (CASTRO, 2018).

Almada (2013) reforça a necessidade de estudar a psicologia cognitiva para perceber as ações e agravos decorrentes de $\mathrm{SB}$, diretamente relacionados ao profissional e ao seu ambiente de trabalho. Por isso, suas contribuições para a prevenção e cura do esgotamento profissional são extremamente úteis.

Os sintomas de depressão e de SB são bem semelhantes, o que realmente difere esses agravos à saúde, é que a $\mathrm{SB}$ aparece exclusivamente no ambiente de trabalho (SHIMITZ, 2015).

Nos estudos de Souza et al., (2012) os policiais que estão em risco e vitimização necessitam de uma atenção, momento de escuta, acompanhamento de uma equipe multidisciplinar. Para isso é necessário mais estudos e investimento na psicologia da saúde ocupacional para atendimento a esses pacientes.

E no caso específico da policial feminina, Urbani et al., (2019) e Dantas et al., (2010) destacam a necessidade de uma atenção e cuidado diferenciado, pois as mulheres apresentam o nível de estresse mais elevado do que os homens o que interfere na qualidade de vida, saúde e trabalho. Algumas podem apresentar disfunção da articulação temporomandibular (DTM). Como a DTM não é muito comentada na literatura científica, esses autores sugerem desenvolvimento de estudos nessa área.

E por fim, Oliveira e Santos (2010) acrescentam, em seus estudos, a necessidade de levantar dados descritivos acerca da problemática, com a finalidade de os próprios policiais perceberem a condição de sua saúde mental. Esses autores observaram que as 
corporações de policiais não apresentam em seu quadro um setor de psicologia específico que atenda, oferecendo suporte clínico para conter os sintomas de SB. Na maioria dos casos, os policiais são geralmente afastados de seu posto.

\section{CONSIDERAÇÕES FINAIS}

No Brasil, a segurança pública exige uma atenção maior, especialmente por parte do Estado. Os policiais sofrem com problemas de saúde, com a falta de suporte para lidarem com a violência, com o risco de morte, especialmente ao se engajarem em alguma operação de risco, entre outros fatores, como pressão e cobranças dentro seu ambiente de trabalho. O cansaço físico e a falta de equilíbrio emocional podem levar esses profissionais a assumirem diferentes atitudes durante crises e situações caóticas. Assim, essas respostas podem levar à falta de eficácia no desempenho do exercício profissional, expondo os policiais e a população a perigos em potencial.

A saúde mental, física e emocional deve ser motivo de preocupação e cuidado, nas mais variadas esferas de trabalho. $O$ estressse ocupacional está intimamente ligado à satisfação e realização profissional. Se essa relação não está em harmonia, haverá prejuizos à saúde, como foram evidenciados neste estudo, ao ser abordado a SB.

Sendo assim, realizar monitoramento constante da saúde dos policiais, atendimento psicológico e psiquiátrico, verificação das condições de trabalho (QVT), valorização pessoal e salarial, conversas e escutas no ambiente de trabalho para minimizar problemas interpessoais, entre outros, são estratégias que podem contribuir com a saúde dos policiais. Essas medidas são necessárias, especialmente por ser um trabalho que atinge $O U$ repercute gravemente o psicológico desses profissionais. Em outras palavras, os policiais, por lidarem constantemente com situações adversas nas ruas das cidades, por correrem risco e estaem vulneráveis o tempo todo, devem ser assistidos constantemente para que seu corpo e sua mente tenham saúde e assim consigam desempenhar o seu trabalho da melhor forma.

Enfim, este estudo não tem a intenção de oferecer garantias para que os policiais com SB sejam assistidos pelos órgãos competentes, mas busca contribuir com a discussão sobre o tema e incentivar uma reflexão sobre este problema que tem muita 
importância social: a garantia da saúde física e mental daqueles que são responsáveis pela segurança do cidadão.

\section{REFERÊNCIAS}

ABREU, Klayne Leite de et al. Estresse ocupacional e Síndrome de Burnout no exercício profissional da psicologia. Psicol. cienc. prof. [online]. 2002, vol.22, n.2 [cited 2020-10-27], pp.22-29. Disponível: $<$ http://www.scielo.br/scielo.php?script=sci_arttext\&pid=SI4I498932002000200004\&lng=en\& $\mathrm{nrm}=$ iso $>$ ISSN I4149893. https://doi.org/10.1590/Si414-98932002000200004.

ALMADA, R. Cansaço dos bons: a logoterapia como alternativa ao desgate profissional. Cidade Nova, São Paulo, 2013.

ANDRADE, J. de S. Estresse Ocupacional, Hardiness e Qualidade de vida profissional de Policiais Militares de uma cidade do interior de Mato Grosso do Sul. UNIVERSIDADE CATÓLICA DOM BOSCO (UCDB) MESTRADO EM PSICOLOGIA Campo Grande - MS, 2013.

BEZERRA, C. de M.; et al. Estresse ocupacional em mulheres policiais Ciência \& Saúde Coletiva, I8(3):657-666, 2013.

BOCCATO, V. R. C. Metodologia da pesquisa bibliográfica na área odontológica e o artigo científico como forma de comunicação. Rev. Odontol. Univ. Cidade São Paulo, São Paulo, v. 18, n. 3, p. 265-274, 2006.

BRASIL. Ministério da Saúde. Estresse. Brasília: Ministério da Saúde. 2015. Disponível em: http://bvsms.saude.gov.br/dicas-em-saude/2068-estresse. Acesso em Io maio 2020.

BRASIL. Ministério da Saúde. Síndrome de Burnout: causas, sintomas, tratamentos, diagnóstico e prevenção. Brasília: Ministério da Saúde. 2018. Disponível em: http://portalms.saude.gov.br/saude-de-a-z/saude- mental/sindrome-de-burnout. Acesso em io maio 2020 .

CÂNDIDO, J; SOUZA, L. R. de. Síndrome de Burnout: as novas formas de trabalho que adoecem. Psicologia.pt, 2017. ISSN 1646-6977.

CARVALHO, A. V. de. Terapia cognitivo-comportamental na síndrome de Burnout: contextualização e intervenções / organizado por Anelisa Vaz de Carvalho. - Novo Hamburgo : Sinopsys, 2019. 416p.

CASTRO, M. C. et al. Saúde mental do policial brasileiro: tendências teórico metodológicas. Sicologia, Saúde \& Doenças, 2019, 20(2), 525-541 
CASTRO, E. K. de. Bases teóricas da psicologia da saúde / Elisa Kern de Castro, Eduardo Augusto Remor, (Organizadores). - I. ed. - Curitiba: Appris, 2018.

CHAVES, M. S. R. S. , SHIMIZU, I. S. Síndrome de burnout e qualidade do sono de policiais militares do Piauí. Rev Bras Med Trab. 2018;16(4):436-4I. COUTO, M. T., GOMES, R. Homens, saúde e políticas públicas: a equidade de gênero em questão. Ciência e Saúde Coletiva, 2012. I7(Io), 2569-2578.

DANTAS, M. A. et al. Avaliação de estresse em policiais militares. Psicologia: Teoria e Prática - 2010, 12(3):66-77.

FARIA, D. G. R. O profissional de segurança pública: desempenho de seu papel num cenário estressante, de violência e de riscos: um estudo exploratório. 2000. Dissertação (Mestrado em Psicologia). Instituto de Psicologia - Universidade de São Paulo, São Paulo, 200o. Disponível em: https://bdpi.usp.br/item/ooro88123. Acesso 12 maio 2020.

FERREIRA, D. K de S. et al. Condições de Trabalho e Morbidade Referida de Policiais Militares, Recife-PE, Brasil. Saúde Soc. São Paulo, v.21, n.4, p.989-100o, 2012.

FIRME, Eva. ALVES, Joana. ROQUE, Rita. Síndrome de Burnout. 2006/2007. Disponível em: Burnout_trab_final.pdf. Acesso em o8 maio 2020.

GENUÍNO, S. L. V. P; GOMES, M da S; MORAES, E. M. de. O estresse ocupacional e a Sindrome de Burnout no ambiente de trabalho: suas influências no comportamento dos professores da Rede Privada do Ensimo Médio de João Pessoa. Revista Anagrama. São Paulo, v.3, n.2, 2009. Disponível em: http://www.revistas.usp.br/anagrama/article/view/35426. Acesso em I5 maio 2020.

LIMA, F. R. B. de. et al.; Identificação preliminar da síndrome de burnout em policiais militares. Motricidade (C) Edições Desafio Singular 2018, vol. I4, n. I, pp. 150-156 6은 ISSC.

LIPP, M. E. N.; MALAGRIS, L. E. N. O estresse profissional e seu tratamento. In: RANGE, B. (Org.). Psicoterapias cognitivo-comportamentais. São Paulo: Artmed, p.475-490, 2001.

LIZ, C. M. de. et al. Características ocupacionais e sociodemográficas relacionadas ao estresse percebido de policiais militares. Revista Cubana de Medicina Militar, 2014;43(4):467-48o. Disponível: www.scielo. Acesso 2I maio 2020.

MINAYO, M. C. S. et al. Impacto das atividades profissionais na saúde física e mental dos policiais civis e militares do Rio de Janeiro (RJ, Brasil). Ciência \& Saúde Coletiva, I6(4):2199-2209, 2011.

OLIVEIRA, K. L. de; SANTOS, L. M. dos. Percepção da saúde mental em policiais militares da força tática e de rua. Sociologias, Porto Alegre, ano I2, no 25, set./dez. 2010, p. 224-250. 
OLIVEIRA, P. L. M. de; BARGADI, M. P. Estresse e comprometimento com a carreira em policiais militares. Boletim de Psicologia. São Paulo, v.59, n.131, 2009. Disponíve: http://pepsic.bvsalud.org/scielo.php. Acesso em I5 maio 2020.

PELEGRINI, A. et al. Percepção das condições de trabalho e estresse ocupacional em policiais civis e militares de unidades de operações especiais. Cad. Bras. Ter. Ocup., São Carlos, v. 26, n. 2, p. 423-430, 2018.

ROSSETTI, M. O.; EHLERS, D. M.; GUNTERT, I. B. O inventário de sintomas de stress para adultos de Lipp (ISSL) em servidores da polícia federal de São Paulo. Revista brasileira terapias cognitivas 4(2): I08-120, 2008.

SARTORI, L.F; CASSANDRE, M.P; VERCESI, C. Burnout em Policiais: a Relação entre o Trabalho e o Sofrimento. Enanpad. Rio de Janeiro. 20o8. Disponível: http://www.anpad.org.br/admin/pdf/GPR-B906.pdf. Acesso em I5 maio de 2020.

SCHMITZ, G A. Síndrome de Burnout : uma proposta de análise sob enfoque analítico-comportamental / Giliane Aparecida Schmitz. - Londrina, 2015. $59 \mathrm{f}$

SILVA, L. C. da; SALLES, T. L. de A. O estresse ocupacional e as formas alternativas de tratamento. ReCaPe Revista de Carreiras e Pessoas São Paulo. Volume VI - Número o2 - Mai/Jun/Jul/Ago 2016.

SOUZA, E. R. de. et al. Sofrimento Psíquico de Policiais Militares. Cad. Saúde Pública, Rio de Janeiro, 28(7):1297-131I, jul, 2012.

SUDA, E. Y.; COELHO, A. T; BERTACI, A. C.; SANTOS, B. B. Relação entre nível geral de saúde, dor musculoesquelética e síndrome de burnout em professores universitários. Fisioterapia e pesquisa, I8 (3), 270-274, 2011.

TRIGO, T. R.; TENG, C. T.; HALLAK, J. E. C. Síndrome de burnout ou estafa profissional e os transtornos psiquiátricos. Arch. Clin. Psychiatry, v. 34, n. 5, p. 223-233, 2007 .

URBANI, G. et al. Síndrome da disfunção da articulação temporomandibular e o estresse presente no trabalho policial: revisão integrativa. Ciência \& Saúde Coletiva, 24(5):1753-1765, 2019.

VIEIRA, I; RUSSO, J. A. Burnout e estresse: entre medicação e psicologização. Physis vol.29 no.2 Rio de Janeiro 2019 Epub Sep i6, 2019. Disponível: https://doi.org/10.1590/so103-73312019290206. Acesso 25 de maio 2020.

ZAPPELLINI, M. B; FEUERSCHUTTE, S. G. O uso da triagulação na persquisa científica brasileira. Disponível: https://doi.org/ro.13058/raep.2015.vi6n2.238. Acesso em 22 maio 2020. 